\title{
Intermediate FMR1 alleles and cognitive and/or behavioural phenotypes
}

\author{
Irene Madrigal $^{1}$, Mar Xunclà ${ }^{2}$, Maria Isabel Tejada ${ }^{3,4}$, Francisco Martínez ${ }^{4,5}$, Isabel Fernández-Carvajal ${ }^{4,6}$, \\ Luís Alberto Pérez-Jurado ${ }^{7}$, Laia Rodriguez-Revenga ${ }^{1}$ and Montserrat Milà ${ }^{\star 1,1,8}$
}

\begin{abstract}
During the last few years, several studies have reported an excess of intermediate $F M R 1$ alleles in patients with cognitive and/or behavioural phenotypes. Here, we report the frequency of intermediate alleles (IAs) in three pathologies, intellectual disabilities (IDs), attention-deficit/hyperactivity disorder and autism, from different Spanish regions. We found 142 IAs among 9015 patients with ID (1.6\%), 4 among the 415 ADHD patients $(0.96 \%)$ and 4 among the 300 autistic patients (1.3\%), similar to the frequency reported in our control population. No evidence was found of an excess of IA at the FRAXA locus in any of the study populations, although geographical variability was detected. Moreover, the analysis of 100 transmissions of IAs showed that $95 \%$ of these alleles were stable. Only $3 \%$ expanded within the same range and $2 \%$ expanded to a full mutation in two generations. No evidence of an association between IAs and behavioural or cognitive phenotypes was found, suggesting that IAs are not clearly implicated in these pathologies.
\end{abstract}

European Journal of Human Genetics (2011) 19, 921-923; doi:10.1038/ejhg.2011.41; published online 23 March 2011

Keywords: intermediate alleles; cognitive and behavioural phenotypes; FMR1; ASD; ADHD

\section{INTRODUCTION}

Fragile X syndrome (FXS, no. 300624) is the most common form of inherited intellectual disabilities (IDs), with an estimated incidence of 1 in 4000 males and 1 in 8000 females. ${ }^{1,2}$ The molecular basis of this syndrome is mainly the expansion of an unstable region of CGG repeats in the $5^{\prime}$-untranslated region of the FXS gene (FMR1). The CGG repeat of the FMR1 gene is distributed in the population in four allelic classes. Alleles ranging from 6 to 44 CGG repeats are the most common in the general population and have stable transmission to the next generation. Expansion of the repeat region to more than 200 CGG trinucleotide sequences, called full mutation, leads to hypermethylation of the CpG island and the expanded CGG region, resulting in non-expression of the FMR1 gene and absence of the FMR1 protein (FMRP). The lack of FMRP is the direct cause of the FXS phenotype. ${ }^{3}$ Expansions of about 55-200 repeats, called premutation alleles, are associated with a significant elevation of FMR1 mRNA levels, ${ }^{4}$ and it has been known that carriers of FMR1 premutation have a risk of developing fragile $\mathrm{X}$-associated tremor/ataxia syndrome, a late-onset neurodegenerative disorder. ${ }^{5,6}$ Premutation alleles are generally unstable, resulting in an expansion of the CGG repeat sequence when passed from mother to child. Offspring of female premutation carriers is at risk of having FXS. Finally, alleles within the 45-54 CGG repeat range are described as 'intermediate' alleles (IAs), as they may show some instability, including expansion to a full mutation in two generations, ${ }^{7-9}$ although they have not been observed to expand to full mutations in only one generation.

During the last few years, several population studies have been undertaken to determine the frequency of IA of the FMR1 gene both in the general population and among persons with ID and/or behavioural phenotypes. A study of patients with ID in the Brazilian population ${ }^{10}$ reported a higher frequency of IA alleles in ID boys (6.3\%) than in normal male controls $(2.4 \%)$. In a similar study in a Southern England cohort of ID patients, ${ }^{11}$ an unexpected excess of IA alleles of $4 \%$ was found compared with $2.4 \%$ for controls. However, other studies failed to replicate these results. ${ }^{12-16}$

To contribute additional data towards resolving this controversy, we undertook a survey to determine whether IAs are found at a greater frequency among a large Spanish cohort of males with behavioural and/or cognitive phenotypes.

\section{SUBJECTS AND METHODS}

\section{Patients}

The present study was designed to determine the frequencies of intermediate FMR1 alleles (defined in the range 45-54 repeats) among 9015 males with ID, 415 males affected by ADHD and 300 males affected with autism spectrum disorders. Patients were recruited from many different clinical units all over Spain (Table 1). All patients were referred for fragile X testing, and the diagnosis of fragile X, ADHD and ASD was performed according to DSM-IV criteria. Ages ranged from 18 months to 45 years old. All patients provided informed consent for testing, and the studies were approved by the ethics committees of each participating institution.

\section{Control population}

Frequency of IAs in a control population was determined in a series of 5775 males and 750 women from different Spanish regions (Table 1). The majority of the controls were already available from previous studies: 256 women from the general population were recruited in Cruces Hospital (Barakaldo-Bizkaia;

${ }^{1}$ CIBER de Enfermedades Raras and Biochemistry and Molecular Genetics Department, Hospital Clínic, Barcelona, Spain; ${ }^{2}$ Fundació Clinic per a la Recerca Biomèdica, Barcelona, Spain; ${ }^{3}$ Biochemistry Department, Molecular Genetics Laboratory, Cruces Hospital, Barakaldo-Bizkaia, Spain; ${ }^{4}$ GIRMOGEN (Spanish Network for Mental Retardation), Spain; ${ }^{5}$ Unidad de Genética, Hospital Universitario La Fe, Valencia, Spain; ${ }^{6}$ Instituto de Biología y Genética Molecular (IBGM), Universidad de Valladolid, Centro Superior de Investigaciones Científicas (CSIC), Valladolid, Spain; ${ }^{7}$ CIBER de Enfermedades Raras, Genetics Unit, Universitat Pompeu Fabra, Program in Molecular Medicine, Barcelona, Spain; 8Institut d'Investigacions Biomèdiques August Pi i Sunyer, Barcelona, Spain

*Correspondence: Dr M Milà, CIBER de Enfermedades Raras and Biochemistry and Molecular Genetics Department, Hospital Clínic, CNillarroel, 170, 08036 Barcelona, Spain. Tel: +34 932275400 Ext. 2784; Fax: +34 93 2275697; E-mail: mmila@clinic.ub.es

Received 13 December 2010; revised 8 February 2011; accepted 9 February 2011; published online 23 March 2011 
Table 1 Sample distribution according the geographical origin

\begin{tabular}{|c|c|c|c|c|}
\hline $\begin{array}{l}\text { Geographical } \\
\text { origin }\end{array}$ & $\begin{array}{c}\text { ID } \\
\text { patients }\end{array}$ & $\begin{array}{c}A D H D \\
\text { patients }\end{array}$ & $\begin{array}{c}A S D \\
\text { patients }\end{array}$ & Controls \\
\hline North & $21420^{\star}$ & - & - & 2569 \\
\hline East & 1550 ठ & - & - & 494 \\
\hline Northwest & 570 o & - & - & 5500 ○ \\
\hline Northeast & 47530 & 415 ऽ & 300 o & 2750 \\
\hline Total & 90150 & 415 ఠ & 300 o & $5775 \delta / 750$ 우 \\
\hline
\end{tabular}

published by Tejada and $\operatorname{Duran}^{17}$ ); 496 women from the general population were recruited in Hospital Universitario La Fe (Valencia); 5500 newborns (part of these data are published by Fernandez-Carvajal et al $^{18}$ ) were recruited in Universidad de Valladolid (Valladolid) and 275 males from the general population were recruited in Hospital Clínic of Barcelona.

\section{Molecular analysis}

Molecular analysis of the FMR1 CGG repeat region was performed in different laboratories following the same method by PCR amplification using fluorescentlabelled primers, as previously described. ${ }^{19}$ The reaction product was analysed on an ABI310 (Applied Biosystems, Foster City, CA, USA). Data generation and evaluation have been performed in different centres following similar procedures. PCR products were purified using the Montage Sequencing Reaction Cleanup (Millipore Corporation, Billerica, MA, USA), and automatically sequenced using the BigDye Terminator v3.1 Cycle Sequencing Kit (Applied Biosystems) and an ABI3100 automatic sequencer (Applied Biosystems).

\section{Statistical analysis}

A $Z$-test with $95 \%$ confidence interval was performed to compare IA frequencies among control and patient populations.

\section{RESULTS}

\section{Frequency of IAs in behavioural and/or cognitive phenotypes}

A total of 9015 patients with ID, 415 diagnosed with ADHD and 300 with ASD have been tested for the CGG repeat tract of FMR1 gene. The percentage of IAs was $1.6 \%$ (142/9015) among ID patients, $0.98 \%$ (4/415) among ADHD patients and $1.33 \%$ (4/300) among ASD patients. The frequency of IA in males from the general population was 3.5\% (204/5775). No evidence for an excess of IA at the FRAXA locus in ID, ADHD or ASD populations was detected, but a significant higher frequency was observed in the control population $(Z=7.598$, $P<0.05$ for ID; $Z=1.88, P<0.05$ for ADHD; and $Z=2.665, P<0.05$ for ASD). We investigated whether this fact was because of the different geographical origin of the samples, as the majority of controls proceeded from the Northwest and most of the cases were from the Northeast of Spain. When comparing the frequency of IA in ID with controls belonging to the same Spanish region, no significant differences were obtained $(P<0.05)$. The IA frequencies differed between the four Spanish regions studied, the North of Spain showed the lowest and Northwest the highest (Table 2). Table 3 shows the distribution of IA in males with ID and male control samples in different populations.

\section{Stability of IAs}

Analysis of 100 transmissions showed that alleles of 45-54 repeats are at low risk to expand to full mutations in a single generation. The vast majority of the IAs remained stable and five were unstable; three of which expanded within intermediate range (+1-2 CGG) and only two jumped to full mutation in two generations. A total of 31 IAs, including 4 of the 5 unstable alleles, were further characterised by
Table 2 Frequency of IA in the Spanish population

\begin{tabular}{lllr}
\hline & $\begin{array}{c}\text { IA frequency } \\
\text { in ID patients }\end{array}$ & \multicolumn{1}{c}{$\begin{array}{c}\text { IA frequency } \\
\text { in controls }\end{array}$} & \multicolumn{1}{c}{$\begin{array}{c}\text { Z-test, } \\
\text { P-value }\end{array}$} \\
\hline North & $0.8 \%(17 / 2142)$ & $0.8 \%(4 / 512)$ & $-0.255, P>0.05$ \\
East & $1.3 \%(21 / 1550)$ & $1.1 \%(11 / 988)$ & $0.346, P>0.05$ \\
Northwest & $3.2 \%(18 / 570)$ & $3.6 \%(199 / 5500)$ & $0.445, P>0.05$ \\
Northeast & $1.8 \%(86 / 4753)$ & $1.8 \%(5 / 275)$ & $-0.221, P>0.05$ \\
\hline
\end{tabular}

Table 3 Frequency of IA in males with ID and male control samples in different populations

\begin{tabular}{|c|c|c|c|c|}
\hline Population & $\begin{array}{c}\text { CGG repeats' } \\
\text { range }\end{array}$ & $\begin{array}{l}\text { IA frequency in } \\
\text { ID patients (\%) }\end{array}$ & $\begin{array}{c}\text { IA frequency } \\
\text { in controls (\%) }\end{array}$ & Reference \\
\hline UK & $41-60$ & 4.4 & $2.9^{a}$ & Youings et a/ ${ }^{11}$ \\
\hline Brazil & $40-60$ & 6.4 & $2.8^{a}$ & Haddad et al ${ }^{10}$ \\
\hline Tasmania & $41-60$ & 3.4 & 2.4 & Mitchell et al ${ }^{12}$ \\
\hline USA & $41-60$ & 4.3 & 4.0 & Crawford et a/ ${ }^{13}$ \\
\hline Canada & $40-54$ & 4.2 & 3.7 & Patsalis et al ${ }^{14}$ \\
\hline Cyprus & $40-54$ & 3.5 & 4.3 & Patsalis et al ${ }^{14}$ \\
\hline France & $40-55$ & 2.8 & 2.2 & Mornet et al15 \\
\hline
\end{tabular}

Comparison of studies reported in the literature. aStatistically significant difference.

the sequencing of the FMR1-expanded region (Table 4). One of the alleles that expanded to full mutation in two generations was uninterrupted, and the other showed 52 CGG repeats with two AGG interruptions in a 10-9-31 pattern that expanded to a premutated allele of 56 CGG, which did not contain any AGG interruptions (Table 4).

\section{DISCUSSION}

The role of FMR1 IA in behavioural and/or cognitive phenotypes is controversial. Some studies ${ }^{10,11}$ have reported an excess of these alleles in ID cohorts, suggesting a possible phenotypic effect in the intellectual functioning. Others, including the present study, have failed to replicate these results (listed in Table 3). The frequency of IA in the general population shows geographical variability that ranges from 2.8 to $6.4 \%$. Indeed, differences in FRAXA repeat distributions have been reported between several ethnic groups, even among Caucasians. ${ }^{13,20,21}$ Furthermore, the lack of consensus about the IA range definition increases this variability among analysed populations. In the present study, we used an IA range between 45 and 54 repeats, being the same for patients and controls. A geographical variation was observed, with the lowest frequency detected in the North of Spain and the highest in the Northwest. We hypothesise that the high rate of IA in this population may be due to the low immigration rate in this region, thereby making this a very closed and autochthonous population, in contrast to other regions such as Northeast, North or East of Spain. In fact, the frequency of IA in Caucasian populations is higher, for example, than in Africans. ${ }^{13}$ The low IA frequency observed in the North could be explained by the presence of 'pure' Basque individuals. Recently, Arrieta et al ${ }^{22}$ reported that the frequency of IA in a 'pure' Basque population was $10 \%$. They established a range for IA within 35-54 CGG; but the frequency of IA within 45-54 used in the present study was $0 \%$, which may explain the low IA frequency in our North population. 
Table 4 Stability of intermediate alleles

\begin{tabular}{|c|c|c|}
\hline & $\begin{array}{l}\text { CGG repeats' first } \\
\text { generation }\end{array}$ & $\begin{array}{l}\text { CGG repeats' second } \\
\text { generation }\end{array}$ \\
\hline \multirow[t]{5}{*}{ Unstable alleles $(n=4)$} & 46 & $50(50)$ \\
\hline & 45 & 47 (9.9.27) \\
\hline & $52(10.9 .31)^{a}$ & $56(56)$ \\
\hline & $45(45)^{a}$ & $80(80)$ \\
\hline & $45(19.25)$ & - \\
\hline \multirow{5}{*}{$\begin{array}{l}\text { Stable alleles with one or no } \\
\text { AGG interruptions }(n=6)\end{array}$} & $49(49)$ & - \\
\hline & $48(9.38)$ & - \\
\hline & $51(9.41 ; n=2)$ & - \\
\hline & $54(9.44)$ & - \\
\hline & $45(9.9 .25)$ & - \\
\hline \multirow{10}{*}{$\begin{array}{l}\text { Stable alleles wit more than } \\
\text { one AGG interruption }(n=21)\end{array}$} & $46(9.9 .26)$ & - \\
\hline & $47(9.9 .27 ; n=2)$ & - \\
\hline & $48(9.9 .28 ; n=4)$ & - \\
\hline & $49(9.9 .29 ; n=2)$ & - \\
\hline & $50(9.9 .8 .21)$ & - \\
\hline & $50(9.9 .30)$ & - \\
\hline & $51(9.9 .31 ; n=2)$ & - \\
\hline & $52(9.9 .32)$ & - \\
\hline & $53(9.9 .33 ; n=2)$ & - \\
\hline & $54(9.9 .34 ; n=3)$ & - \\
\hline
\end{tabular}

alA that jumped to full mutation in two generations (published in Fernandez-Carvajal et al ${ }^{8}$ and Zuniga et $a^{9}$ ). The AGG interspersion pattern is shown in parenthesis.

A high frequency of IA has also been associated with an increased risk of behavioural phenotypes. Specifically, Loesch et $a l^{23}$ found an association of IA with an increased risk of autistic behaviour. Nevertheless, considering the small sample size analysed $(n=42)$, this affirmation required studies with larger cohorts. In this study, we determined IA frequency in two independent cohorts of ASD and ADHD patients, but no significant association was found.

At the FRAXA loci, both the length and the purity of the repeat have an important role in stability; AGG repeats interrupting the CGGs are thought to provide stability during replication and hence avoiding expansion. ${ }^{24}$ The vast majority of alleles with $<45$ CGG in the general population have repeat tracks with two AGG interruptions, and repeat instabilities are rare for these alleles. Data reported in the literature show that IA present similar proportions of unstable transmissions. $^{25,26}$ In our series, 23 sequenced alleles had two or more AGG interruptions and 8 had none or only one AGG interruption, 6 of which remain stable in more than two generations. Even though the two IA that expanded to full mutation had lost the AGG interruptions, all alleles lacking an AGG interruption do not generally expand in the next generation. The loss of the AGG interruptions could be explained by its conversion to CGG, which seems to be a common event in human genome. ${ }^{27}$ The lack of AGG interruptions, together with other unknown genetic factors, probably contributed to repeat instability in the two cases as has been studied by Dombrowski and Morel. ${ }^{26}$

A frequent concern in FXS screening is the genetic counselling to IA carriers. Currently, the follow-up of individuals with no AGG interruptions is indicated, despite the low risk of expansion in the next generation. Our findings show that IAs should not be considered a risk factor for ID or behavioural phenotypes. Nonetheless, these alleles should be characterised to give an accurate genetic counselling.

\section{CONFLICT OF INTEREST}

The authors declare no conflict of interest.

\section{ACKNOWLEDGEMENTS}

We thank the Instituto Carlos III (PS09-00413) and AGAUR from the Autonomous Catalan Government (2009-SGR1337). The 'CIBER de Enfermedades Raras' is an initiative of the ISCIII.

1 Crawford DC, Acuna JM, Sherman SL: FMR1 and the fragile X syndrome: human genome epidemiology review. Genet Med 2001; 3: 359-371.

2 Crawford DC, Meadows KL, Newman JL et al: Prevalence of the fragile $\mathrm{X}$ syndrome in African-Americans. Am J Med Genet 2002; 110: 226-233.

3 de Vries BB, Mohkamsing S, van den Ouweland AM et al: Screening with the FMR1 protein test among mentally retarded males. Hum Genet 1998; 103: 520-522.

4 Tassone F, Hagerman RJ, Taylor AK, Gane LW, Godfrey TE, Hagerman PJ: Elevated levels of FMR 1 mRNA in carrier males: a new mechanism of involvement in the fragile$X$ syndrome. Am J Hum Genet 2000; 66: 6-15.

5 Hagerman RJ, Leehey $M$, Heinrichs $W$ et al: Intention tremor, parkinsonism, and generalized brain atrophy in male carriers of fragile X. Neurology 2001; 57: 127-130.

6 Jacquemont S, Hagerman RJ, Leehey $M$ et al: Fragile X premutation tremor/ataxia syndrome: molecular, clinical, and neuroimaging correlates. Am J Hum Genet 2003 . 72: 869-878.

7 Terracciano A, Pomponi MG, Marino GM et al: Expansion to full mutation of a FMR1 intermediate allele over two generations. Eur J Hum Genet 2004; 12: 333-336.

8 Fernandez-Carvajal I, Lopez Posadas B, Pan R, Raske C, Hagerman PJ, Tassone F: Expansion of an FMR1 grey-zone allele to a full mutation in two generations. $J \mathrm{Mol}$ Diagn 2009; 11: 306-310.

9 Zuniga A, Juan J, Mila M, Guerrero A: Expansion of an intermediate allele of the FMR1 gene in only two generations. Clin Genet 2005; 68: 471-473.

10 Haddad LA, Aguiar MJ, Costa SS, Mingroni-Netto RC, Vianna-Morgante AM, Pena SD: Fully mutated and gray-zone FRAXA alleles in Brazilian mentally retarded boys. Am J Med Genet 1999; 84: 198-201.

11 Youings SA, Murray A, Dennis N et al: FRAXA and FRAXE: the results of a five year survey. J Med Genet 2000; 37: 415-421.

12 Mitchell RJ, Holden JJ, Zhang $\mathrm{C}$ et al: FMR1 alleles in Tasmania: a screening study of the special educational needs population. Clin Genet 2005; 67: 38-46.

13 Crawford DC, Meadows KL, Newman JL et al: Prevalence and phenotype consequence of FRAXA and FRAXE alleles in a large, ethnically diverse, special education-needs population. Am J Hum Genet 1999; 64: 495-507.

14 Patsalis PC, Sismani C, Hettinger JA et al: Frequencies of 'grey-zone' and premutationsize FMR1 CGG-repeat alleles in patients with developmental disability in Cyprus and Canada. Am J Med Genet 1999; 84: 195-197.

15 Mornet E, Chateau C, Simon-Bouy B, Serre JL: The intermediate alleles of the fragile $X$ CGG repeat in patients with mental retardation. Clin Genet 1998; 53: 200-201.

16 Otsuka S, Sakamoto $Y$, Siomi $H$ et al: Fragile $X$ carrier screening and FMR1 allele distribution in the Japanese population. Brain Dev 2010; 32: 110-114.

17 Tejada MI, Duran M: Screening for female fragile X premutation and full mutation carriers. A commentary on the work of Wildhagen et al. Community Genet 1999; 2: 49-50.

18 Fernandez-Carvajal I, Walichiewicz P, Xiaosen X, Pan R, Hagerman PJ, Tassone F: Screening for expanded alleles of the FMR1 gene in blood spots from newborn males in a Spanish population. J Mol Diagn 2009; 11: 324-329.

$19 \mathrm{Fu}$ YH, Kuhl DP, Pizzuti $A$ et al: Variation of the CGG repeat at the fragile $X$ site results in genetic instability: resolution of the Sherman paradox. Cell 1991; 67: 1047-1058.

20 Meadows KL, Pettay D, Newman J, Hersey J, Ashley AE, Sherman SL: Survey of the fragile $X$ syndrome and the fragile $X E$ syndrome in a special education needs population. Am J Med Genet 1996; 64: 428-433.

21 Murray A, Youings S, Dennis $\mathrm{N}$ et al: Population screening at the FRAXA and FRAXE loci: molecular analyses of boys with learning difficulties and their mothers. Hum $\mathrm{Mol}$ Genet 1996; 5: 727-735.

22 Arrieta MI, Ramirez JM, Telez M et al: Analysis of the fragile X trinucleotide repeat in basques: association of premutation and intermediate sizes, anchoring AGGs and linked microsatellites with unstable alleles. Curr Genomics 2008; 9: 191-199.

23 Loesch DZ, Godler DE, Khaniani M et al: Linking the FMR1 alleles with small CGG expansions with neurodevelopmental disorders: preliminary data suggest an involvement of epigenetic mechanisms. Am J Med Genet A 2009; 149A: 2306-2310.

24 Eichler EE, Holden JJ, Popovich BW et al: Length of uninterrupted CGG repeats determines instability in the FMR1 gene. Nat Genet 1994; 8: 88-94.

25 Levesque S, Dombrowski C, Morel ML et al: Screening and instability of FMR1 alleles in a prospective sample of 24,449 mother-newborn pairs from the general population. Clin Genet 2009; 76: 511-523.

26 Dombrowski C, Levesque S, Morel ML, Rouillard P, Morgan K, Rousseau F: Premutation and intermediate-size FMR1 alleles in 10572 males from the general population: loss of an AGG interruption is a late event in the generation of fragile $X$ syndrome alleles. Hum Mol Genet 2002; 11: 371-378.

27 Eichler EE, Hammond HA, Macpherson JN, Ward PA, Nelson DL: Population survey of the human FMR1 CGG repeat substructure suggests biased polarity for the loss of AGG interruptions. Hum Mol Genet 1995; 4: 2199-2208. 